\title{
Experimental Action Research on Improving Student's Classroom Participation: The Case of Samara University Economics Students of 2019 G.C.
}

\author{
Dagmawe Menelek Asfaw", Abdurhman Kedir, Belayneh Asmare, Mohammed Adem \\ Department of Economics, College of Business and Economics, Samara University, Samara, Ethiopia \\ Email address: \\ dagmawemenelek@gmail.com (D. M. Asfaw) \\ ${ }^{*}$ Corresponding author \\ To cite this article: \\ Dagmawe Menelek Asfaw, Abdurhman Kedir, Belayneh Asmare, Mohammed Adem. Experimental Action Research on Improving Student's \\ Classroom Participation: The Case of Samara University Economics Students of 2019 G.C.. Science Journal of Education. \\ Vol. 9, No. 2, 2021, pp. 50-57. doi: 10.11648/j.sjedu.20210902.15
}

Received: June 19, 2020; Accepted: April 13, 2021; Published: April 23, 2021

\begin{abstract}
Education is a means by which people develop and acquire knowledge, skills, values and attitudes. It paves the way for development and plays vital role (serve as a catalyst) in bringing socio-cultural, economical, technological, political and environmental advancements. In case of our country, the government takes different measures to enhance the development; one is by education. But our education system faces different challenges. Among them is our students are not taking learning as their own responsibility rather they consider it as a fulfillment of having some kind of certificate. In short, they are not actively participating in the classroom. This study tries to address how to improve classroom participation in economics students from Samara University by Appling experimental action research. In doing so, the results of the study were, before policy intervention the classroom participation were so weak and poor which was only $14 \%$ of students were participate from total number of students in the classroom; whereas after policy intervention classroom participation were so nice compare to before, which was $40 \%$ of students were participate from total number of students in the classroom. At the end of the day the researchers were recommended that the concerned body could undertake the inside mentioned policy interventions (actions taken) for sustainable improvement of students' classroom participation.
\end{abstract}

Keywords: Policy Intervention (Action Taken), Classroom Participation, Samara University

\section{Introduction}

\subsection{Background of the Study}

Education is a means by which people develop and acquire knowledge, skills, values and attitudes. It paves the way for development and plays vital role (serve as a catalyst) in bringing socio-cultural, economical, technological, political and environmental advancements. However, to achieve these goals or to attain quality education, the teaching learning process at all educational institutions should be supported by strong two way communications (teacher students or student's students) meaning active participation had better observed during the whole course provision sessions [3].

Our country, Ethiopia is now taking different measures to use education for development. Among the mechanisms to list a few are; expanding the universities more than 43 nationwide and also different university colleges and technical vocational schools, increase the intake capacities of universities 100,000 and above each year, creating a university-industry linkage, making the intake capacity of universities $70 \%$ for science and technology and $30 \%$ for social science which can support the country for its development in technology, and also introducing active learning methods in all Ethiopian Universities. Our University (Samara University) also adopts active learning methods and now we are just practicing it. According to Education Sector Development Programme IV (ESDP IV) It is necessary therefore to shift attention to quality concerns in general and to those inputs and processes which translate more directly into improved student learning and which help change the school into a genuine learning environment (such 
as: quality-focused school supervision, increased student participation, school-community partnerships). When we see the literature, the views of learning theorists such as Vygotsky on learning and instruction challenge the wisdom of traditional pedagogic practice quite significantly [1].

William, M. [15] however, argues that activity based learning is influenced by institutional and interactive social factors; whereas Vygotsky's theory characterizes learning as an individual's concrete perception of real world objects. He states, moreover, that cognitive learning takes place through social interactions through which knowledge is internalized. The traditional classroom regards learning as a process of student absorption of knowledge that has been pre-digested and imparted by the teacher. The new approach emphasizes active participation of both the learner and the teacher. One of the advantages of student participation is that it offers the possibility of the variety of viewpoints exploring the particular individual view of students as well as the general organizing principles that help to make the topic as a whole. It also provides an opportunity to share experience with other students and teachers (Robert Fisher 2005).

General agreement exists about the importance of participation in university education; for instance, enabling students to become involved in their own learning and enjoy their learning process [12]. Other benefits of participation include increases in student's commitment and better understanding and critical thinking [5]. Furthermore, student participation has been shown to encourage active learning, improve work habits and develop specific skills, which are key ingredients for success in the professional world. While the teaching in the tertiary setting is acknowledged to have some exceptions, largely this rule of learning remains the same at all levels of teaching and learning. Biggs, J [2] highlights the need for some changes in tertiary teaching and instructional design to bring about better teaching and learning outcomes. He further states that according to Halligan (1988), reciprocity is a hallmark of good interaction, especially in pupil-pupil exchange, which enhances learning. This emerges as a common criterion for 'good quality' interaction in arrange of teaching-learning contexts.

Biggs, J [2] Further suggests that active learners are able to achieve a higher level of engagement and thus a higher level of cognitive learning in their academic work. This study, which clearly demonstrates that when students interact more intensely their performance improves, supports Biggs assertion. Even if our government takes different measures to achieve a better goal by the education system; there are different challenges that the education in the universities face. Among them the basic one is our students are not active participant in the classroom. Thus there is a strong need to create active and responsible citizens that could participate in achieving core objectives. Here, because of this we need to improve the participation of students in the classroom by creating different mechanisms.

\subsection{Statement of the Problem}

In today's world; Education has been transformed as to be a means for achieving ones' own need and this can be accomplished by implementing active learning. In the earlier times students are considered as to be an empty poet that the teacher will fill knowledge by lecture method without an active involvement of students in the classroom i.e. by considering students as passive learners, so that they have no room for participation and discussion in the classroom. In contrary to the above assertion; there is a constructivist approach for learning that students should have to play great role for their own learning and take a responsibility. The advocators of constructivists consider (ideas) should have to be constructed by the learner by themselves, if so education will be very interesting and fruitful. This means that we have to use active learning methods so that students will interact with their environment and discuss with their colleagues. And also Students learn best when learning is active: When they are mentally involved, when they engage in hands-on activities, when they are involved in a process of inquiry, discovery, investigation, and interpretation. Thus, learning is enhanced when students repeat the information in their own words or when they give examples or make use of the information, when students are passive, their brain doesn't do job of processing effectively or retaining the information efficiently [4].

When we come to our country, the Ministry of Education (MOE) is advocating active learning approach in all our more than 43 universities. The government has been implementing various strategies, policies and capacity building efforts to promote active teaching and learning process.

This is to create a paradigm shift from teacher centered approach of leaning which has been done for many years in the country to student centered approach. The recently adopted modularization approach is a typical example of the country's commitment to implement student centered approach. Higher diploma program (HDP) is also one of the capacity building efforts of promoting active methods of teaching and learning process. However the designing and implementation of such policies and programs could not be effective if the students in every class taking various courses are not actively participating in the teaching and learning process. Many studies have indicated that the academic performance and class participation of students is diminishing from time through the country. When the students were given some activities to be done in group, they didn't do it; instead, they waited for lecture from their teacher. This made students always to wait others rather than try to do by their own. This problem is much prevalent in low achiever students than their active counter parts. This also confirmed by the experience and observation of the researchers in their respective classes at Samara University. Due to this an action research were conducted on to improve the low level participation in classroom in the case of third year economics students of Samara University.

\subsection{Objectives of the Study}

The general objective of the study is "Improving student's 
classroom participation: a case of samara university third year economics students of 2019 G.C".

Specific objectives of the Study

In line with the general objective, the following specific objectives are sated. These are

1) To assess the level of participation of students in the classroom.

2) To identify teaching methods which encourage/discourage students to participate in the classroom?

3) To identify factors that hinder students from participation.

4) To identify factors to enhanced student's participation.

\section{Literature Review}

Volumes of literature have been written regarding the value and importance of student participation in classroom discussion. Few, if any, instructors (particularly at the college level) would dispute the position that students who participate in class learn more. This is, after all, how most of us feel we learn the best. However, actual evidence to support this hypothesis seems somewhat lacking. Rather, for most educators, it is almost intuitive that creating an environment where students freely converse and share ideas cannot help but foster a better understanding of course material and an appreciation for what it means to be a mature learner and thinker. But educators must be cautious in their assertions. Today's teachers must be aware of our weaknesses and strengths. A number of studies have been carried out in the past to determine the effectiveness of teaching and learning strategies and a number of methods have been proposed. However, these strategies cannot be applied in every teaching and learning situation, particularly in multicultural tertiary settings, and they need careful consideration while being implemented in such situations. There is a need to identify how these strategies can be applied most effectively into the classroom, giving special consideration to a various factors and the mechanisms in the learning process, such as time allocation for the task, applying the correct teaching strategy, the teaching learning environment and the quality of instruction to engage the students in the learning task. These entail the level of student involvement in the class discussion and the learning activity.

As argued by Beck, S. [1] the learning process depends on the level of student-student interaction and student-teacher interaction in a conducive learning environment. The formation of appropriate interactive groups and the effective use of materials with clear instructions are essential tools in the teaching-learning process. William, [15] states that Vygotsky's common concept in his writing about learning, the 'Zone of Proximal Development', indicates that range of skill the learner is developing but has not yet been able to master. He strongly believes that what a learner is able to achieve with assistance at one point in time, he or she will eventually be able to do unaided. If learning inside the classroom is done through interaction, the learners develop the skills through peer assistance, and hence become able to do it on their own. McIlrath [10] strongly believe that models are very effective in facilitating action research in learning and teaching. One way of applying these models is for teacher scholars to look critically at their own teaching strategies, frequently conducting research in their own classrooms to find out the effectiveness of their methods. His discussion on the model of learning clearly focuses on a number of issues. One of these is the dominance of time and the quality of instructional inputs. He argues that sufficient time allocations and opportunity for practice and remedial intervention are essential for archiving the required level of mastery of the subject. In this research we analyze our interaction with the students in the teachinglearning process. In the context of our, students may be characterized as passive learners, for whom it has been found that classroom interaction tends to be a one-way process. The present study uses observation to investigate this aspect of weakness in the teacher-student interaction process. Another crucial factor in effective teaching and learning is the correct implementation of cooperative learning. Many studies have shown that correct implementation of the technique yields improved results in acquisition and retention of the subject and contribute to the development of interpersonal communication skills and self-confidence [8].

Oakley [11] strongly believe that students should be involved in discussion that is strongly interactive. This enhances student cooperation for positive learning outcomes and confidence building. According to Johnson [7] where group interactions are strong, student learning outcomes are more desirable and a higher level of self-esteem is achieved. This produces a more open learning environment where students speak out more freely with confidence and acquire related skills. Additionally, students involved in interaction in classroom learning tend to display higher motivation to learn, especially intrinsic motivation. By this process the students are also encouraged to assist their peers, thus promoting more effective learning. Where the instructor intends to apply interactive learning, specific strategies are need. This has to be identified and practiced in a constructive way to monitor group characteristics and behavioral trends to maximize the interaction and hence the learning process [7]. Instructors' input in the interaction process also influences the learning process in many important ways, particularly learners' attitudes towards the instructor, the peers and the subject matter. Johnson [7] argues that clarity of instructions is instrumental in both the interaction process and the learning outcomes, strongly support structuring of the classroom to facilitate cooperative work among students, which they point out is an essential feature in interactive strategies. Researchers argue that discussing issues with one another in the group and supporting each other's' ideas with reasoning enhances student learning and builds self-confidence. Further, they argue that a strong sense of positive interdependence among group members builds better coordination and helps in the exchange of ideas [7]. The results of this study support these views. Moreover, Johnson, [7] found in their research that cooperation is preferred to be 
the dominant interaction pattern in the classroom compared to the competitive or individualistic setting [9]. They found that in a cooperative setting, achievement improved and learners developed a more positive attitude towards the subject. At the same time, they found that the positive response is not universal; students who were reluctant to interact with others may be negatively affected.

Therefore, caution is needed when interactive learning is being encouraged, to recognize that such learners need special attention to develop the right attitude towards the interactive process. This requires the application of appropriate instructional strategies as the instructor monitors the program in operation.

The formation of groups is also an important task in the process of enhancing interaction. The instructors should be instrumental in the formation of groups based on appropriate strategy to enhance the interaction. For example, weaker students should be coupled with the stronger ones, to facilitate the learning and interaction. Failing to do this could result in adverse outcomes for the weaker groups, which could have long term adverse outcomes. Normally, the stronger students tend to seek other stronger ones leaving the weaker students to group with each other [11].

If stronger and weaker students are combined in the groups, the weaker ones are able to gain from the stronger students in tackling the assigned tasks. In this way, but indirectly, the weaker students are receiving peer tutoring. On the other hand, the stronger students gain confidence in the subject matter and are encouraged to interact, reinforcing the teaching and learning process [11]. They further argue that continued interaction could transform the pair groups into effective teaching-learning team. It is important therefore, to set out clear guidelines for team functioning and formulate a common set of expectations for the group task. Time is another factor that affects learning outcomes. McIlrath [10] supports Proctor's (1984) claim that in academic learning time is one of the process predictors of student achievement. McIlrath [10] Further state that student involvement, as defined by Carroll (1963) refers to the engagement time or time-on-task. This implies that the time given to the students for a particular task determines the learning outcome.

\section{Methodology}

\subsection{Description of the Study Area}

There are five independent countries in the horn of Africa and Ethiopia is one of those countries located in the horn of Africa. The country is divided into 9 regions among which the Afar national State is one. "Samara" is the regional capital city of this state. The state comprises of a population size of around 1.5 million people. The Afar national Regional state is known for its unique tourist attraction areas some of which are globally recognized such are the Erta ale active volcano, Lucy, Dallol Depression and many others. Samara University is a newly established pioneer academic institution located in Ethiopia specifically situated at
"Samara" town which is the regional capital of the Afar National Regional State. The University is located with a distance of $1.5 \mathrm{kms}$ farther from the Ethio-Djibouti international high-way that connects Ethiopia with Djibouti. Samara University is the only university in the world that is situated in the same town with LUCY (the oldest human being) having a distance of $1.5 \mathrm{kms}$ in between them. The faculty of business and economics is one of the major faculties which want operational in 2007 at the time the university started enrolling students. It is running four departments offering undergraduate degree namely economics, management, accounting \& finance and administrative services management. The Economics program is one of the undergraduate degree programs given at Samara University. The opening of the program is in line with the country's efforts towards developing an efficient utilization of its resources in a sustainable way. The importance and need for planned development of available resources of the country can hardly be overstated. Though Ethiopia is endowed with a large amount of natural resources, critical shortage of capacity has greatly hindered the development of the country. The development of available resources must be a central element of the country's strategy to improve the quality of life of its people. The Department of Economics at Samara University was launched in 2001 with the objective of addressing the country's trained human power shortage in the field of economics. On the community services aspect, currently the department is undertaking four researches in collaboration of the university. Furthermore, the department is also undertaking study on the estimation of the regional Gross Domestic Product (RGDP) for the year 2004E.C of Afar National Regional State (http//www.su.edu.et/node/44).

\subsection{Sampling Techniques}

We were selected all (both section A and B) third year economics students which are 75 in number as a target population by using purposive sampling techniques from all Bach of economic students, after all we were also selected section B as a sample for this study using simple random sampling techniques (lottery method). The reason for selected third year economic students is, all researchers in this action research is teaching those third year economics student. This help us to make policy intervention (action) easily, and follows, assess and evaluate the post intervention results nearby. Therefore they are better suited for our action research project other than second and first year students. The overall data and practices was carried out in history of economic thought, rural development, development planning $\&$ project analysis, industrial economics as subject sessions.

\subsection{Research Design}

The study was both qualitative and quantitative type of research, because both numerical and non-numerical data were collected during the study by observation and interview with the students in the classroom. 


\subsection{Type and Source of Data}

The study used both primary and secondary data. The primary data were collected through observation and interview from third year economic students. The secondary type of data also collected from published and unpublished materials which are from authorized and authenticated organizations such as department documents, journals, etc. The sources of data for this study were basically third year economics students of Samara University.

\subsection{Method of Data Collection}

Qualitative and quantitative data were collected using interview and observation from the class selected for this research. As a quantitative approach, before intervention the observation was carried out for two months in class for their participation in first semester, particularly a check list were used for two days per a week for last two month of which how many students were participated in the course of history of economic thought, rural development, development planning \& project analysis, industrial economics on average, interview was conducted with those students who are inactive in class participation to what makes them passive in the class. In addition to this, interview was conducted with students who seat at the backside. As a qualitative approach, before the intervention, allowing students to give independent opinions on the effectiveness of the teaching methods. The literature provides support to the methods chosen in this research.

After intervention (action taken) as a quantitative approach, the observation was carried out for one months in class for their participation in second semester, particularly a check list were used for two days per a week for last one month of which how many students were participated in the course of history of economic thought, rural development, development planning \& project analysis, industrial economics on average.

\subsection{Data Analysis}

The data which was found by interview and observation for the specific objectives of research was analyzed through descriptive statistical tools (frequencies, percentages, standard deviations and mean) with the help of Statistical Package for Social Science (SPSS) Version 20 and micro-soft Excel and analyzed through narration thematically.

\section{Data Presentation and Analysis}

The findings of the study can be put in relation to our specific objectives of the study that we found from the interview and observation. These data collection tools were used to address our specific objectives of the study as much as possible.

Table 1. Checklist before the intervention.

\begin{tabular}{|c|c|c|c|c|c|c|c|c|c|c|}
\hline \multirow{2}{*}{ Day (s) } & \multicolumn{3}{|c|}{ Total Number of students in the classroom } & \multicolumn{3}{|c|}{ Number of students participated } & \multicolumn{3}{|c|}{ Number of students not participated } & \multirow{2}{*}{$\begin{array}{l}\text { Remark } \\
\text { Absent }\end{array}$} \\
\hline & Female & Male & Total & Female & Male & Total & Female & Male & Total & \\
\hline Day 1 & 4 & 33 & 37 & 0 & 4 & 4 & 4 & 29 & 33 & 2 \\
\hline Day 2 & 2 & 34 & 36 & 0 & 6 & 6 & 2 & 28 & 30 & 3 \\
\hline Day 3 & 3 & 36 & 39 & 0 & 2 & 2 & 3 & 34 & 37 & 0 \\
\hline Day 4 & 4 & 28 & 32 & 0 & 7 & 7 & 4 & 21 & 25 & 7 \\
\hline Day 5 & 1 & 33 & 34 & 0 & 6 & 6 & 1 & 27 & 28 & 5 \\
\hline Day 6 & 4 & 33 & 37 & 0 & 5 & 5 & 4 & 28 & 32 & 2 \\
\hline Day 7 & 3 & 32 & 35 & 0 & 8 & 8 & 3 & 24 & 27 & 4 \\
\hline Day 8 & 2 & 36 & 38 & 0 & 9 & 9 & 2 & 27 & 29 & 1 \\
\hline Day 9 & 4 & 32 & 36 & 0 & 1 & 1 & 4 & 31 & 35 & 3 \\
\hline Day 10 & 1 & 37 & 38 & 0 & 2 & 2 & 1 & 35 & 36 & 1 \\
\hline Day 11 & 4 & 26 & 30 & 0 & 8 & 8 & 4 & 18 & 22 & 9 \\
\hline Day 12 & 2 & 30 & 32 & 0 & 3 & 3 & 2 & 27 & 29 & 7 \\
\hline Day 13 & 3 & 36 & 39 & 0 & 9 & 9 & 3 & 27 & 30 & 0 \\
\hline Day 14 & 4 & 27 & 31 & 0 & 1 & 1 & 4 & 26 & 30 & 8 \\
\hline Day 15 & 3 & 34 & 37 & 0 & 7 & 7 & 3 & 27 & 30 & 2 \\
\hline Day 16 & 3 & 26 & 29 & 0 & 2 & 2 & 3 & 24 & 27 & 10 \\
\hline
\end{tabular}

N.B:- The total numbers of students were 39 out of this number 35 were male and 4 also female.

\subsection{Magnitude (Level) of Participation}

From above Table 1 Out of a total number 39, on average 35 (out of which 32 was male and 3 was female) students were attend the class per day. From this average total number of the students who attend the class, 5 students were participated per day in the course of history of economic thought, rural development, development planning \& project analysis, industrial economics on average; that means on average 31 students were inactive in a day. From this all female students were inactive to classroom participation and only 5 male students were participated per day. As we have seen from the above Table 1 female student's classroom participation were $0 \%$ from the total average number of female students and male students classroom participation also $15 \%$ from the total average number of male students in the classroom before intervention. In general the overall participation of the class was $14 \%$ from the total average number of students in the classroom per day, this indicated that the classroom participation was too poor and none of female students were participate in the classroom. 


\subsection{Teaching Method of the Instructor}

In case of the teaching method, from the information we get by observation and interview for inactive students it has a great impact on students' participation in class and some students account their inactivity the teaching methods that teachers use. Even if the university is practicing active teaching methods not all of the instructors are implementing it correctly as it is planned as we get from the information with informal discussions. Some of the factors instructors listed are; class size, class schedule, etc...The students said that it would be better for them to use active teaching methods so that they will participate better in the classroom. The students also arise that lecturing (teacher oriented) method of teaching was the one factor that hinder their classroom participation.

\subsection{Factors that Hinder/Enhance Student's Classroom Participation}

From the average ${ }^{1}$ of total inactive students; $90 \%$ were seated at the back of the class. Female students at the back of the class account 94\%. From the students interviewed for their low participation in class, $60 \%$ were due to afraid of their incorrect response, $23.45 \%$ were due to language problem and $16.55 \%$ were due to their background. In case their seating position in the class, those students who seat at the middle area of the class were mostly those students with background problem that is problems like not participated before, with less background knowledge, etc... But $86 \%$ of the interviewed students have chosen the back side (back bencher) because of their assumption that a teacher can't ask them. Students assume that they are out of control, if they seat at the backside. Another reason that students may not participate in class is because of their own personal fears of feeling inadequate in front of others, regardless of the logistics of the classroom setting. From the data it would be concluded that students may feel intimidated or inadequate in front of their classmates and teachers, and thus choose not to participate. Students even reported confidence as the most motivating factor for their participation in class.

Finally almost all students said that active learning method (group discussions, presentations and demonstrations) is a means for their active classroom participation. The findings of the study revealed that $75 \%$ of students assured that group discussions gave them more chance to participate in the class freely compared to presentation and demonstrations. The remaining $25 \%$ of students were also interested in presentations and demonstrations, of course, these students were amongst high and medium academic result achievers. In addition to this decent teachers characteristics, course type, pleasant classroom also factors that are enhance student's classroom participation.

Generally In this study, the researcher found different

1 We have been took total number of inactive students from each course of history of economic thought, rural development, development planning \& project analysis, industrial economics and made average of total number of inactive students. factors that are directly related to the low classroom participation. As we have seen in the data presentation and analysis part of this study, most of our students are not participated in class. Based on this problem and the objective "Improving classroom participation" the researcher had been devised different action strategies/interventions were taken like; positive reinforcement, using active teaching methods, behave our characteristics, changing the seating arrangement, giving advice for those who are in need, etc...

\section{Intervention/Action Taken}

\subsection{Actions Taken/Intervention}

There are so many students who are not active participant in the class. Thus there is a need to take an action. To improve students' participation in class, so many action strategies were taken.

The following are among the action strategies taken:

1. Positive reinforcement for those who make other students active in their one to five arrangement; this can be done by first using by their one to five arrangement at the beginning of the class and mostly one student is active in their group so we will give a positive reinforcement for him for what he did in the classroom for his group members.

2. Introducing the next session topic and tell them to prepare a short not on that topic and read it finally they can come with some idea; this can be done by giving a handout and told them to read in their one to five group arrangement.

3. For those students with the afraid of different factors, corresponding psychological advice was given depending on the issues that make students to be inactive by the instructors.

4. The seating arrangement of the students' was exchanged depending on the nature of the problem this can be done by arranging their one to five in a way that they can rotate with in some interval of days.

5. Ask for new hands or for some new people to speak, ask students on opinion questions learn students' names and call them by their names, ask students meaningful questions, and finally control the students who are over participators in economics second year students there is one students who can control the class, we made other students to participate so that it will not always given the chance for him rather it will be distributed for others.

6. Tried to use pleasing words like "thank you very much, keep it up", it was helpful for students.

7. Tried to use body language, for example actions for the learners to get the meaning of words.

8. Tried to know giving gifts would help or not? (like pen and exercise book)

9. Tried to tell interesting and short stories at the beginning of each lesson; the stories will help learners to be interested in the lesson. 


\subsection{Post Policy Intervention (Action Taken) Results}

Table 2. Checklist after the intervention.

\begin{tabular}{|c|c|c|c|c|c|c|c|c|c|c|}
\hline \multirow{2}{*}{ Day (s) } & \multicolumn{3}{|c|}{ Total Number of students in the classroom } & \multicolumn{3}{|c|}{ Number of students participated } & \multicolumn{3}{|c|}{ Number of students not participated } & \multirow{2}{*}{$\begin{array}{l}\text { Remark } \\
\text { Absent }\end{array}$} \\
\hline & Female & Male & Total & Female & Male & Total & Female & Male & Total & \\
\hline Day 1 & 3 & 35 & 38 & 2 & 10 & 12 & 1 & 25 & 26 & 1 \\
\hline Day 2 & 2 & 35 & 37 & 1 & 13 & 14 & 1 & 22 & 23 & 2 \\
\hline Day 3 & 4 & 34 & 39 & 0 & 12 & 12 & 4 & 22 & 27 & 0 \\
\hline Day 4 & 4 & 31 & 35 & 3 & 14 & 17 & 1 & 17 & 18 & 4 \\
\hline Day 5 & 1 & 38 & 39 & 1 & 12 & 13 & 0 & 26 & 26 & 0 \\
\hline Day 6 & 3 & 33 & 38 & 2 & 16 & 18 & 1 & 17 & 20 & 1 \\
\hline Day 8 & 2 & 35 & 37 & 1 & 12 & 13 & 1 & 23 & 24 & 2 \\
\hline
\end{tabular}

N.B:- The total numbers of students were 39 out of this number 35 were male and 4 also female.

By applying the above actions in the classroom and by the results obtained from the observation (see Table 2) Out of a total number 39 , on average 37 (out of which 34 was male and 3 was female) students were attend the class per day. From this average total number of the students who attend the class, 15 students were participated per day in the course of history of economic thought, rural development, development planning \& project analysis, industrial economics on average; that means on average 22 students were inactive in a day. From this 3 female students were active to classroom participation and 13 male students were also participated per day. As we have seen from the above table 2 female student's classroom participation were $66 \%$ from the total average number of female students and male students classroom participation also $38 \%$ from the total average number of male students in the classroom after intervention. In general the overall participation of the class was $40 \%$ from the total average number of students in the classroom per day.

From this we can understand that by applying the above action strategies our students inactivity were more or less changed especially the participation of female students was so nice after intervention. However, there exists a need more research and action undertaken to have a very important change in students participation.

\section{Conclusion and Recommendation}

\subsection{Conclusion}

General agreement exists about the importance of participation in university education; for instance, enabling students to become involved in their own learning and enjoy their learning process. Other benefits of participation include increases in student's commitment and better understanding and critical thinking. Furthermore, student participation has been shown to encourage active learning, improve work habits and develop specific skills, which are key ingredients for success in the professional world. While the teaching in the tertiary setting is acknowledged to have some exceptions, largely this rule of learning remains the same at all levels of teaching and learning. Further states reciprocity is a hallmark of good interaction, especially in pupil-pupil exchange, which enhances learning. This emerges as a common criterion for 'good quality' interaction in arrange of teachinglearning contexts. Therefore in these study we were try to seek a method (mechanism) that are improve student classroom participation by applying experimental action research. In doing so the researcher were collected the data before and after intervention and analyzed each of them separately. The finding before intervention was:- overall participation of the class was $14 \%$ from the total average number of students in the classroom per day, this indicated that the classroom participation was too poor and none of female students were participate in the classroom, and the finding after policy intervention also:- overall participation of the class was $40 \%$ from the total average number of students in the classroom per day. From this we can understand that by applying the above action strategies our students inactivity were more or less changed especially the participation of female students was so nice after intervention.

\subsection{Policy Recommendations}

Our findings evidenced that apply the above policy interventions (actions taken) have a significant impact to improve the classroom participation of economics students in Samara University. Considering university experience, policy results, this study recommends that the concerned body could undertake the above mentioned policy interventions (actions taken) for sustainable improvement of student classroom participation.

\section{References}

[1] Beck, S. W., 2001. Vygotskian Perspectives on Literacy Research: Constructing Meaning through Collaborative Inquiry, England, Cambridge University Press, Cambridge. Vol. 71, No. 2.

[2] Biggs, J. 2003. 'Changing University Teaching' In Teaching for Quality Learning at University London, 2nd Edition, Society for Research into Higher Education and Open University Press.

[3] Bonwell, C., \& Eison, J. (1991). Active learning: Creating excitement in the classroom (ASHE-ERIC Higher Education. 
[4] Bransford, J., Brown, A. and Cocking, R. (2000). "How People Learn: Body, Mind, Experience and School," National Academy Press, Washington D. C.,. Available online athttp://www.nap.edu/html/howpeople1/accessed on June 12, 2014.

[5] Heyman, J., Sailors, J. J. (2011). Peer assessment of class participation: applying peer nomination to overcome rating inflation. Assessment and Evaluation in Higher Education, 36 (5), 605-618.

[6] Johnson, D. W. and Johnson, R. T. 1985. Student-Student Interaction: Ignored but powerful, in 'Research', edited by, Howey, K. R., Journal of Teacher Education.

[7] Johnson, D. W., Johnson, R. T. and Smith, K. A. 1998. Active Learning, Cooperation in a College Classroom. Edina MN: Interaction Book Co.
[8] Kaufman, D. B. and Felder, R. M. 2000. 'Accounting for Individual Effort in Cooperative Learning Teams' Journal of Engineering Education, 89 (2) 133-140.

[9] McIlrath, D. and Huitt, W. 1995, (December). The teaching learning process: A discussion of models. Valdosta, GA: Valdosta State University.

[10] Oakley, B., Felder, R. M., Brent, R. and Elhajj, I. 2004. Turning Student Groups into Effective Teams In Journal of Student Centered Learning, Vol. 2, No. 1, New Forums Press.

[11] O'connor, K. J. (2013). Class participation: promoting in-class student engagement. Education, 133 (3), 340-344.

[12] William, M. 1989. Vygotsky's Social Theory of Mind. Harvard Educational Review, February, 59 (1), 108-126. 